\title{
PREDICTION OF SHIP MOTIONS IN IRREGULAR WAVES BASED ON RESPONSE AMPLITUDE OPERATORS EVALUATED EXPERIMENTALLY IN NOISE WAVES
}

\author{
Sebastian Bielicki \\ Maritime Advanced Research Centre, Gdańsk, Poland
}

\begin{abstract}
The most common methods for predicting ship roll motions in a specified sea state are direct measurements of motions in a representative irregular wave realisation (time domain) or calculations of motions from response amplitude operators (RAOs) in the frequency domain. The result of the first method is valid only for the tested sea state, whilst the second method is more flexible but less accurate. RAO-based predictions are calculated assuming a linear model of ship motions in waves. RAO functions are usually evaluated by means of tests in regular waves for a limited number of frequencies and a constant wave amplitude. This approach is time-consuming and the discrete form of the RAO functions obtained for a limited number of frequencies may lead to discrepancies in the prediction of seakeeping and often does not allow the actual amplitude of the response in resonant frequency to be determined. Another challenge is the appropriate selection of wave amplitude for tests due to the considerable influence of viscous damping on roll response in irregular sea waves. There are alternative methods for the experimental determination of RAO functions and one of them is presented in this study. The presented approach allows RAO functions to be evaluated in one run by the generation of irregular waves characterised by a white or coloured noise spectrum. This method reduces the experiment duration, with almost continuous RAO characteristics obtained. The flat (white noise) and linear (coloured noise) wave spectral energy characteristics are considered in the experiment and the obtained predictions are compared with the results of accurate measurements in irregular waves.
\end{abstract}

Keywords: seakeeping, roll motions, noise, ship motions, experiments

\section{INTRODUCTION}

There are significant challenges concerning the safety and operability aspects of a ship. These issues are especially important for severe sea conditions during operations in open sea. Some may focus on dynamic positioning issues and the influence of ship propulsion systems, such as bow tunnel thrusters on ship motions [1], while others may focus on operability based on the assessment of ship motions as a response to wave excitations [2]. In the last decade, a large number of computational analyses concerning ship motions in waves have been published $[3,4,5,6,7,8]$. However, experiments at the model scale along with full-scale trials [9] are still the most accurate approaches for checking operability criteria, but the cost of model tests sometimes limits the number of considered cases. This study focuses on an experimental approach to roll motion prediction as it plays a very important role in the assessment of ship operability [2], as well as having a significant influence on ship safety during operations in severe seas [10]. These motions are mostly important for station keeping vessels in the offshore industry during operations in the vicinity of platforms in open seas.

Roll motion is the response motion of a vessel exposed to sea waves. The most appropriate method for the prediction of ship response in a seaway is to carry out an experiment in irregular waves representing the considered sea conditions. 
However, this method is usually limited to only a couple of representative sea states. This approach is applicable if the operability is not the main goal of the analysis, meaning that the ship's seakeeping characteristics are regarded as long term and over long distances. For this purpose, the assumption of a linear response of the marine system to random excitation was developed in the first half of the twentieth century.

\section{THEORETICAL BACKGROUND}

The response of ship motions to ocean waves is considered as an input/output system with a known linear characteristic (Fig. 1). This characteristic is called the response amplitude operator (RAO) and is a function of wave frequency [11]. The response motions are irregular like sea waves. By taking a known wave energy spectrum into consideration with a known ship's response frequency characteristic (RAO), the response spectra can be calculated. With response spectra, the statistical properties of this response can be found.

\section{Time Domain}

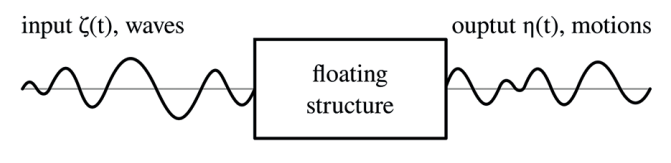

\section{Frequency Domain}

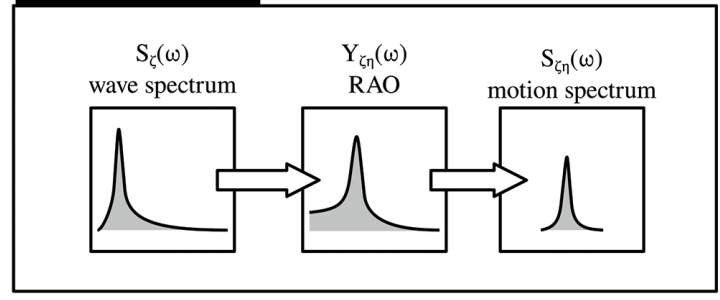

Fig. 1. Linear relationship between wave (input) and motions (response)

Based on an ocean wave representation in spectral form, the wave energy in the frequency domain is given by [12]:

$$
S_{\zeta}(\omega) d \omega=\frac{1}{2} \zeta_{A}^{2}(\omega)
$$

where:

$S_{\zeta} \quad$ - density of wave energy

$d \omega \quad$ - differential of angular frequency

$\omega-$ - wave angular frequency

$\zeta_{A} \quad$ - wave amplitude

and by analogy, the energy spectrum of the response is:

$$
S_{\zeta \eta}(\omega) d \omega=\frac{1}{2} \eta_{A}^{2}(\omega)
$$

where:

$S_{\zeta \eta} \quad$ - density of response energy

$\eta_{A} \quad-$ response amplitude
The linear response characteristic $Y \_\eta$ known as the RAO is:

$$
Y_{\eta}(\omega)=\frac{\eta_{A}(\omega)}{\zeta_{A}(\omega)}
$$

By rearranging Eq. (3), the response amplitude is:

$$
\eta_{A}(\omega)=\zeta_{A}(\omega) Y_{\eta}(\omega)
$$

and by combining Eqs. (2)-(4), the response spectrum may be shown as:

$$
S_{\zeta \eta}(\omega) d \omega=\frac{1}{2} \zeta_{A}^{2}(\omega) Y_{\eta}^{2}(\omega)
$$

Furthermore, when considering Eq. (1), the response spectrum is:

$$
S_{\zeta \eta}(\omega) d \omega=S_{\zeta}(\omega) d \omega Y_{\eta}^{2}(\omega)
$$

The wave and the ship's response are random processes with a Gaussian distribution function around a zero mean [13]; thus, the root mean square value of signal is expressed by:

$$
\eta_{R M S}=\sqrt{m_{0 \eta}}
$$

where the zeroth moment in Eq. (7) is:

$$
m_{0 \eta}=\int_{0}^{\infty} S_{\zeta \eta}(\omega) d \omega .
$$

The above is valid as the response amplitude $\eta_{A}$ is proportional to the wave amplitude $\zeta_{A}$.

The linearized equation of response motion is [12]:

$$
(M+A) \ddot{\eta}+B \dot{\eta}+C \eta=F_{W}
$$

where for linear motions, $F_{W}$ is the wave force acting on a particular direction, and for angular motions, $F_{W}$ is the moment about the axis of rotation. The $M+A$ component is the sum of the inertia properties, such as the mass for linear motions and the moment of inertia for rotations and added mass $A$. The $B$ and $C$ components are hydrodynamic damping and restoring coefficients, respectively. Furthermore, Eq. (9) may be normalised by $M+A$ to reach:

$$
\ddot{\eta}+v_{\varphi} \dot{\eta}+\omega_{\eta}^{2} \eta=f_{W}
$$

where $v_{\eta}$ and $\omega_{\eta}$ are the dimensionless damping coefficient and natural frequency, respectively. The damping coefficient must have a linear characteristic so that the assumption of the proportionality of the response and excitation is valid. This assumption gives a good approximation for all motions except the roll when the nonlinear viscous damping is significantly higher than the damping occurring from the generation of waves. However, the roll motion damping nonlinearity may be included in the equation of motion, if it depends only on the amplitude of the resulting roll motion.

Equation (6) is key to predicting roll motions in the considered sea state with a specified spectral energy 
density $S_{\zeta \eta}(\omega)$. The transfer function of roll motions $Y_{\zeta \varphi}$ is usually established by experiments in regular waves with a constant amplitude or slope, whilst the RAO of roll motion is a narrow band and the tests are carried out for multiple frequencies $\omega$ within a certain range around the resonant frequency $\omega_{\varphi}$. Since viscous damping phenomena depend on the level of roll amplitude, the constant wave amplitude- or slope-based RAO must be corrected to the expected response in the considered sea state. This means that predictions from regular wave experiments should be complemented by the characteristics of roll damping established either by roll decay test or other ones. This approach is thus rather timeconsuming, so this study presents an alternative, less timeconsuming method for RAO evaluation.

Equation (6) may be modified to the form:

$$
S_{N \varphi}\left(\omega_{i}\right)=S_{N}\left(\omega_{i}\right) Y_{\varphi}^{2}\left(\omega_{i}\right)
$$

where the input to the system here is the noise energy density spectrum $S_{N}(\omega)$, which may have a constant value over the frequencies $\omega$ (white noise (WN)) or may proportionally increase (blue noise $(\mathrm{BN})$ ) or decrease (pink noise $(\mathrm{PN})$ ) with the frequencies $\omega$. The $d \omega$ part of the equation is always greater than zero and might be deleted. By transforming Eq. (10), the RAO can be found as:

$$
Y_{\varphi}\left(\omega_{i}\right)=\sqrt{\frac{S_{N \varphi}\left(\omega_{i}\right)}{S_{N}\left(\omega_{i}\right)}} .
$$

The discrete roll motion RAO, in dimensionless form, where the roll angle is related to the wave slope angle $\alpha_{A}=k \zeta_{A}$, can be further approximated by [14]:

$$
Y_{\alpha \varphi}\left(\omega_{i}\right)=\frac{\kappa_{\varphi}}{\sqrt{\left(1-\frac{\omega^{2}}{\omega_{\varphi}^{2}}\right)^{2}+\left(2 v_{\varphi} \frac{\omega}{\omega_{\varphi}^{2}}\right)^{2}}}
$$

where dimensionless damping is found as $v_{\varphi}=\frac{B}{(M+A)}$.

Equation (13) simplifies the ship roll response because sway and yaw coupling is neglected and the contribution of the diffraction component might be compensated by the modified Froude-Krylov heeling moment reduction factor [14]:

$$
\kappa_{\varphi}\left(\omega_{i}\right)=\beta_{0} e^{-\beta_{1} \omega^{2}}
$$

where the coefficients $\beta_{0}$ and $\beta_{1}$ in function are determined by least squares approximation of the RAO evaluated by noise measurements according to Eq. (13). In addition, it is shown that the damping of roll motions in noise waves is equal to the damping in the demanded sea state with the same total energy, meaning that the root mean square (RMS) values of the input waves (noise and wind wave spectral form) are equal. The next key feature of the proposed method is that changes in damping are assumed linear, related to the RMS of the generated noise signal. This means that to find the damping coefficient for the prediction of roll motions, the RMS of the generated noise waves should lay within the RMS values of the demanded sea states. The damping coefficient can be read from the linear characteristic of the RMS values, as shown in Fig. 2.

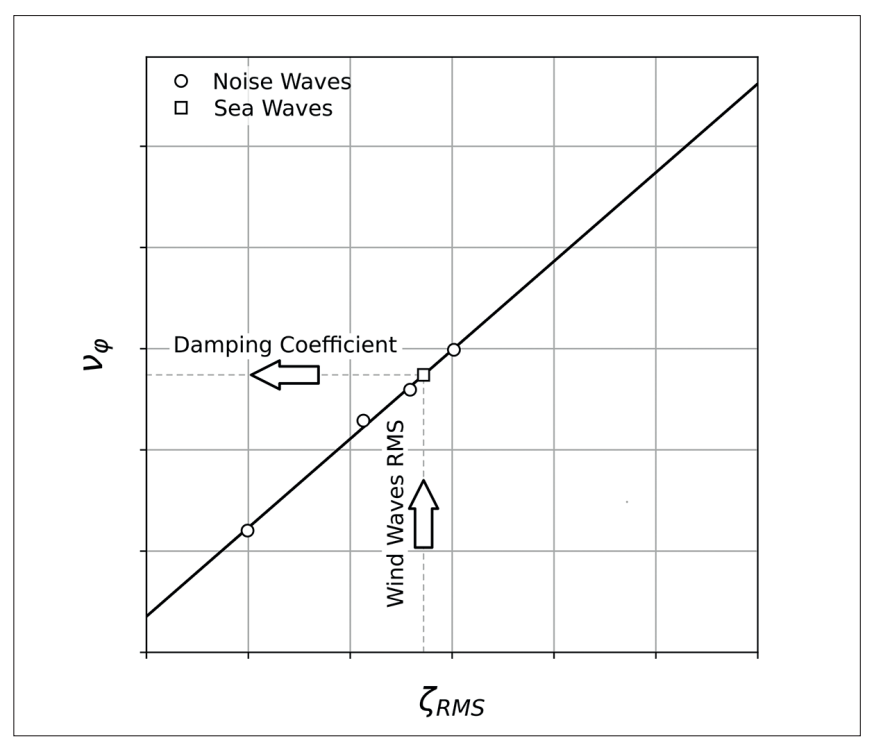

Fig. 2. Linear characteristic of roll damping coefficient

As far as we have a linear characteristic for the damping coefficients from noise measurements, the number of runs may be limited.

\section{MODEL TESTS}

Model tests were carried out for three models of vessels. The tests were carried out in a Maritime Advanced Centre (CTO) towing tank no. 2 equipped with a flap type wave maker and active wave absorber. The rectangular shape tank has a length of $50 \mathrm{~m}$, a breadth of $7 \mathrm{~m}$ and an adjustable depth, which for the purposes of the current analyses was set to represent deep water conditions. The models were tested only in beam seas. The main dimensions of the hull models are presented in Table 1.

Tab. 1. Main particulars of tested hull models

\begin{tabular}{|c|c|c|c|}
\hline & HM\#01 & HM\#02 & HM\#03 \\
\hline$L_{p p}[\mathrm{~m}]$ & 3.585 & 3.553 & 3.212 \\
\hline$B[\mathrm{~m}]$ & 0.708 & 0.770 & 0.952 \\
\hline$T[\mathrm{~m}]$ & 0.196 & 0.205 & 0.363 \\
\hline$C_{B}[-]$ & 0.92 & 0.78 & 0.70 \\
\hline$T \varphi[\mathrm{S}]$ & 2.47 & 2.16 & 3.02 \\
\hline Scale factor & 53.0 & 24.0 & 17.0 \\
\hline
\end{tabular}

The models were tested in different irregular waves representing the demanded sea states and appropriate noise wave realisation [15], [16]. One of the models was tested in regular waves. The detailed configuration of the test cases is presented in Table 2. 


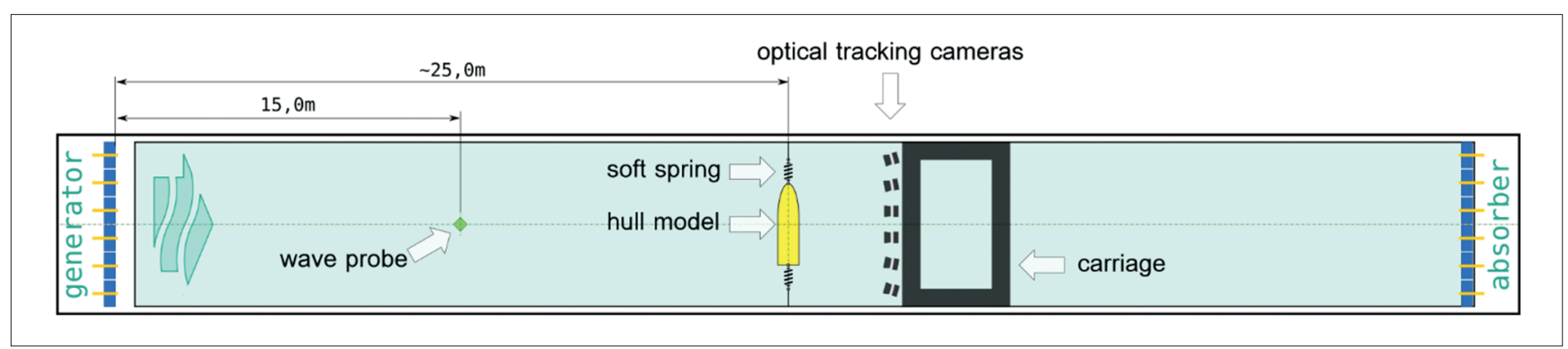

Fig. 3 Experimental setup in CTO towing tank no. 2

\begin{tabular}{|c|c|c|c|c|c|c|c|c|}
\hline $\begin{array}{c}\text { Wave } \\
(\mathrm{HM} \# 01)\end{array}$ & $\begin{array}{l}\text { RMS } \\
{[\mathrm{mm}]}\end{array}$ & $\begin{array}{l}\text { Peak Period } \\
{[\mathrm{s}]}\end{array}$ & $\begin{array}{c}\text { Wave } \\
(\mathrm{HM} \# 02)\end{array}$ & $\begin{array}{l}\text { RMS } \\
{[\mathrm{mm}]}\end{array}$ & $\begin{array}{l}\text { Peak Period } \\
{[\mathrm{s}]}\end{array}$ & $\begin{array}{c}\text { Wave } \\
(\mathrm{HM} \# 03)\end{array}$ & $\begin{array}{l}\text { RMS } \\
{[\mathrm{mm}]}\end{array}$ & $\begin{array}{c}\text { Peak Period } \\
{[\mathrm{s}]}\end{array}$ \\
\hline (ITTC) & & & (JONSWAP) & & & (JONSWAP) & & \\
\hline I1.1 & 12.8 & 2.43 & $\mathrm{I} 1.2$ & 28.8 & 1.42 & I1.3 & 16.8 & 1.85 \\
\hline I 2.1 & 27.2 & 2.45 & $\mathrm{I} 2.2$ & 46.5 & 1.87 & $\mathrm{I} 2.2$ & 36.0 & 2.70 \\
\hline \multirow[t]{2}{*}{ I3.1 } & 36.0 & 2.48 & $\mathrm{I} 3.2$ & 55.9 & 2.00 & $\mathrm{I} 3.2$ & 48.4 & 2.90 \\
\hline & & & I 4.2 & 89.9 & 2.53 & & & \\
\hline (Noise) & & & (Noise) & & & (Noise) & & \\
\hline WN1.1 & 21.3 & & WN1.2 & 37.6 & & WN1.2 & 24.4 & \\
\hline WN2.1 & 25.9 & & WN2.2 & 46.3 & & WN2.2 & 36.0 & \\
\hline WN3.1 & 9.9 & & WN3.2 & 23.8 & & WN3.2 & 48.4 & \\
\hline \multirow[t]{4}{*}{ WN4.1 } & 30.2 & & PN1.2 & 38.4 & & & & \\
\hline & & & PN2.2 & 47.0 & & & & \\
\hline & & & BN1.2 & 36.7 & & & & \\
\hline & & & BN2.2 & 23.1 & & & & \\
\hline \multicolumn{9}{|l|}{ (Regular) } \\
\hline R0.1 & 25.3 & & & & & & & \\
\hline
\end{tabular}

During the tests model was set in perpendicular to wave propagation direction. The wave probe was positioned in front of the model, $10 \mathrm{~m}$ fore from wave generator, and the measured wave train was undisturbed by model itself. The hull motions in 6DOF (degrees of freedom) was measured with the use of 6 motion capture cameras system. Hull model was restrained in sway and surge motions by the soft spring anchoring system mounted to model at the centre line at the water level. The test set up is presented in Fig. 3

The tests in regular waves were carried out in constant regular wave double amplitude of 1/50 of the model length [17]. This level of regular wave amplitude is recommended by procedures issued by the International Towing Tank Conference (ITTC) [17].

The irregular waves were set to represent a wide variety of irregular waves with the most popular wave spectra, such as the ITTC - two parameter Pierson-Moskowitz [18] and JONSWAP [19]. The general parameters representing the generated wave spectra are presented in Table 2 and an example of a measured wave spectrum and its theoretical representation is presented in Fig. 4.

The noise spectra were prepared to obtain a narrow band width as the expected RAO will be within the range of wave

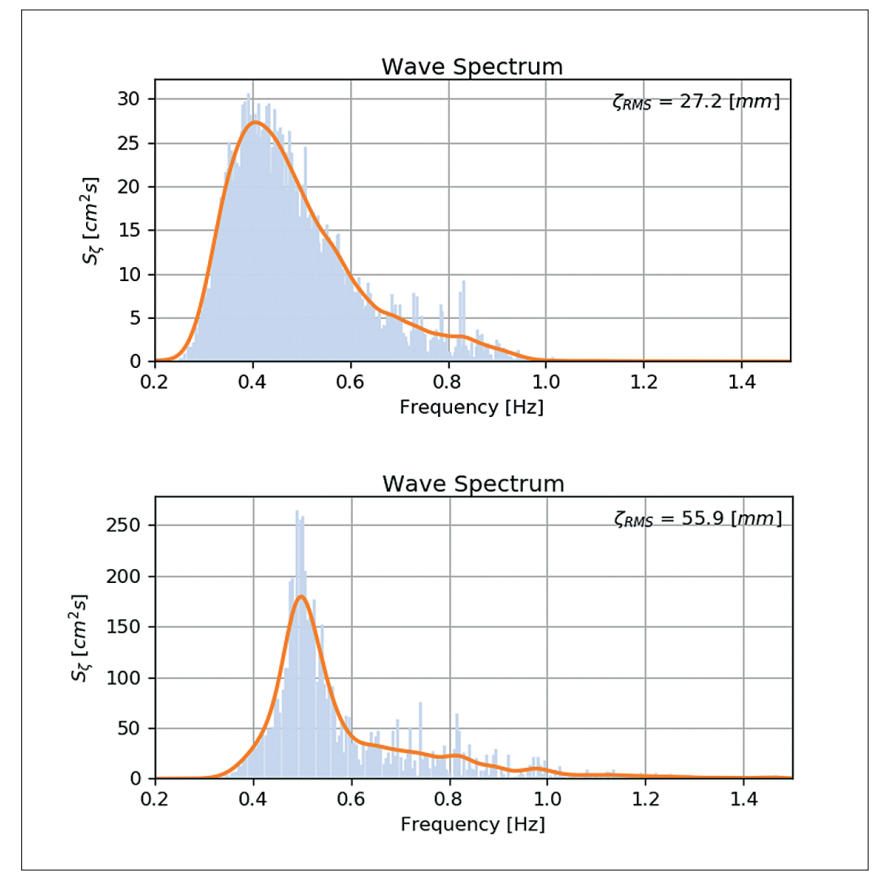

Fig. 4. Spectra of wind waves (top - I2.1 ITTC, bottom - I3.2 JONSWAP) 

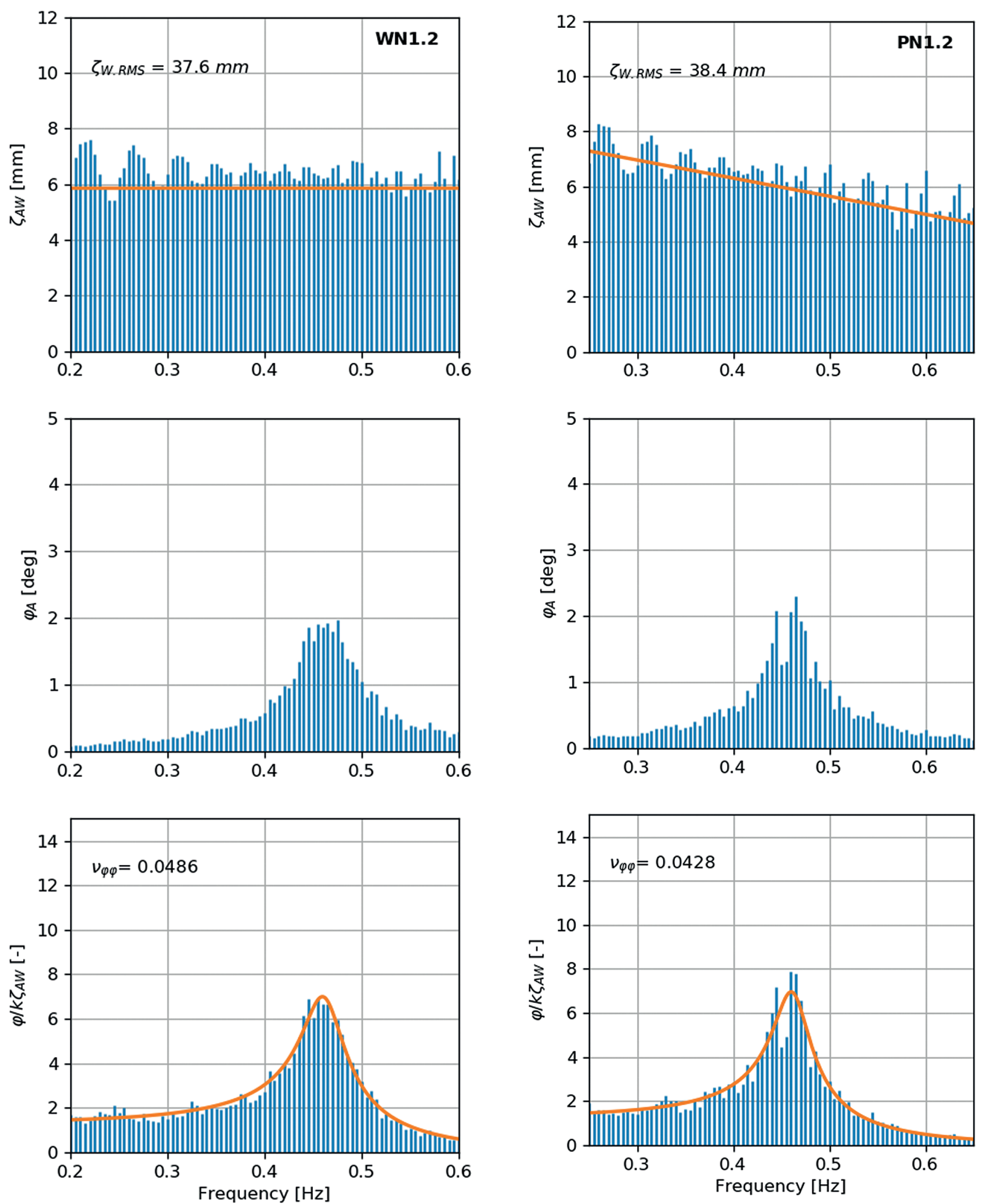

Fig. 5. Comparison of noise measurements - white, HM\#02 (left) vs. pink, HM\#02 (right)

frequencies. In addition, the amplitude of signal was tuned to the energy of noise within the range of the demanded sea energy. Examples of the generated noise amplitude spectra with certain RMS values are presented in Fig. 5 and Fig. 6. 

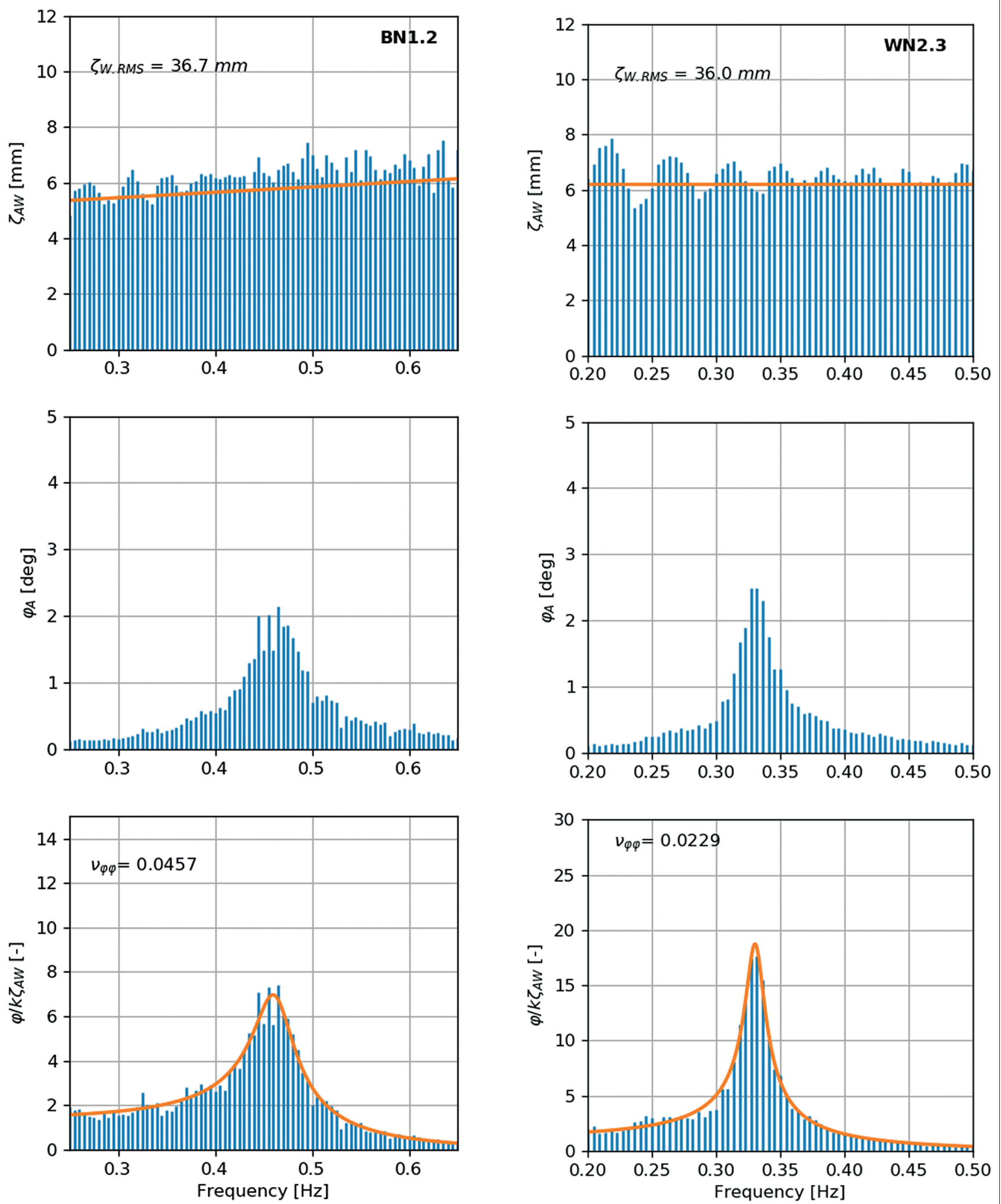

Fig. 6. Comparison of noise measurements - blue, HM\#02 (left) vs. white, HM\#03 (right)

Fig. 7 presents the relationship between the RMS values of the generated noise waves and the damping coefficients achieved from the approximation of RAOs by Eq. (13).
Figures 7-10 present the RAO functions evaluated from the results of measurements in noise waves. 

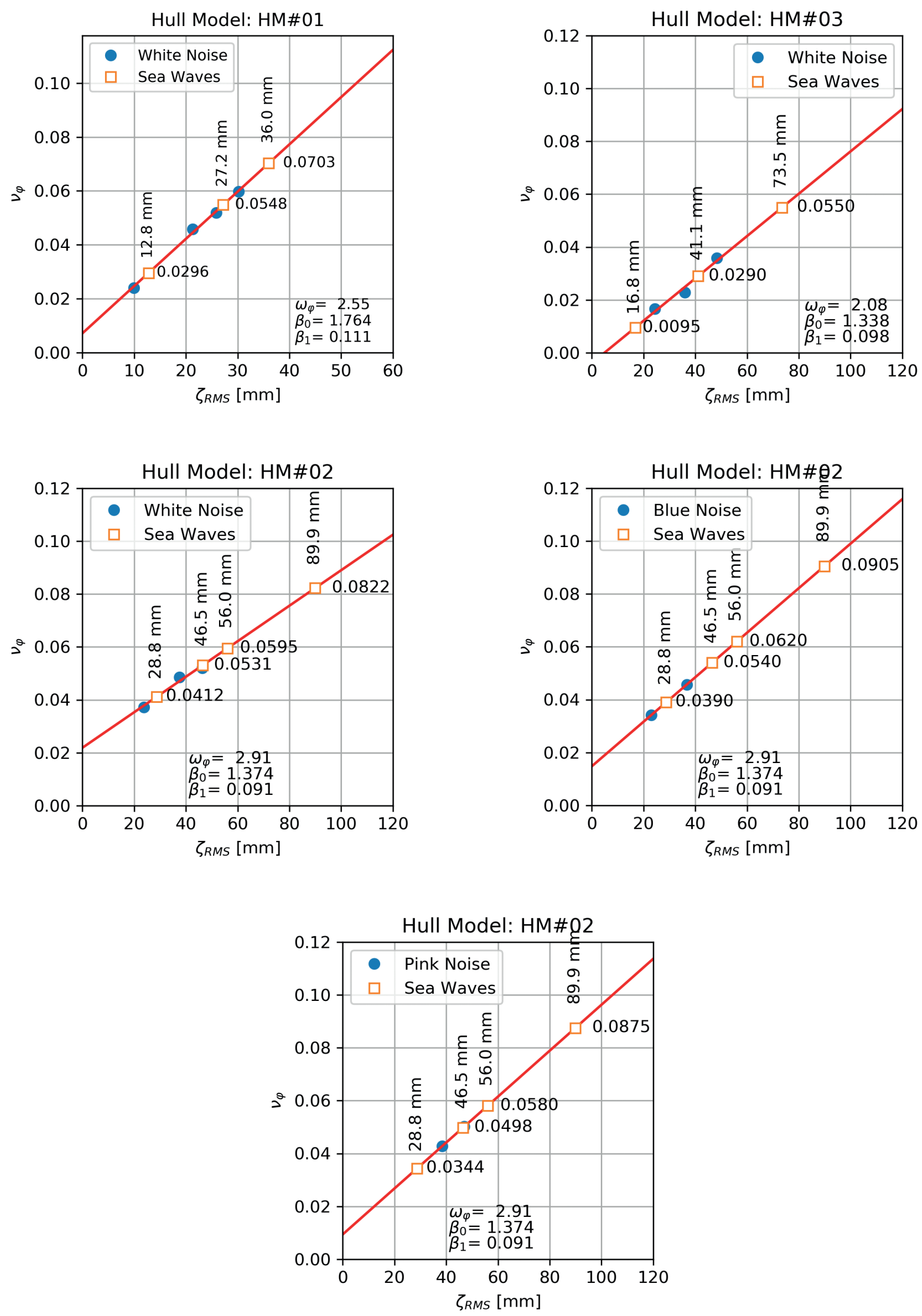

Fig. 7. Relation between damping coefficient and wave RMS 


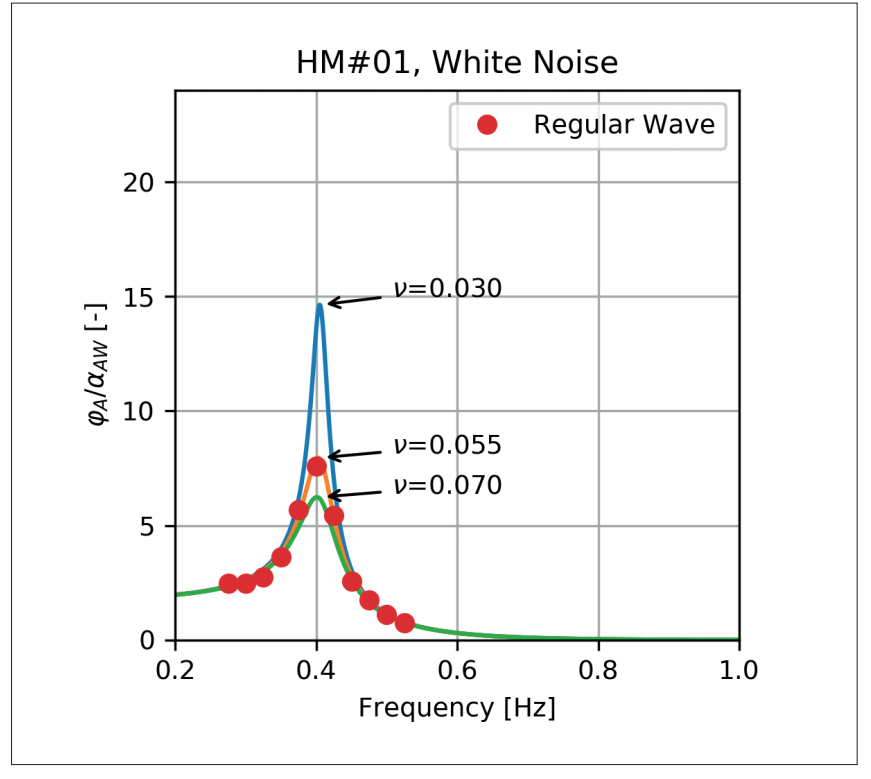

Fig. 8. HM\#01, approximated transfer functions

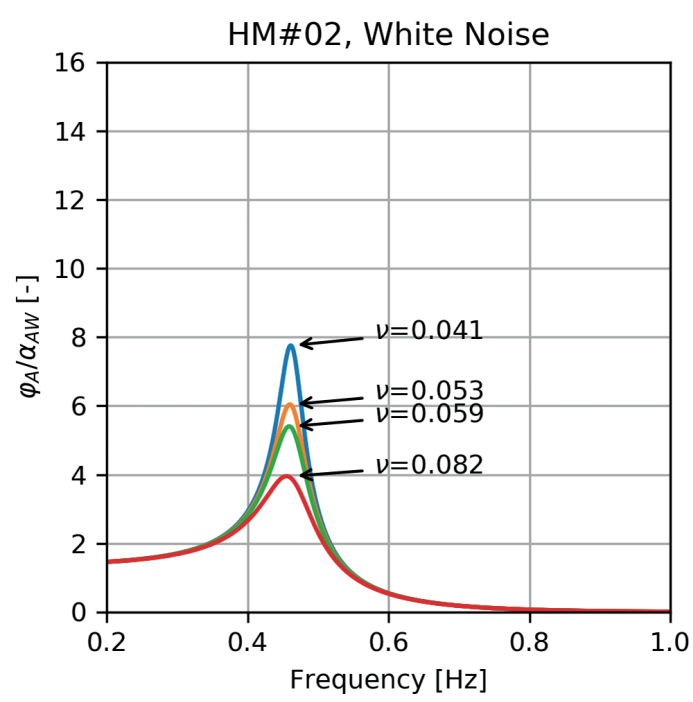

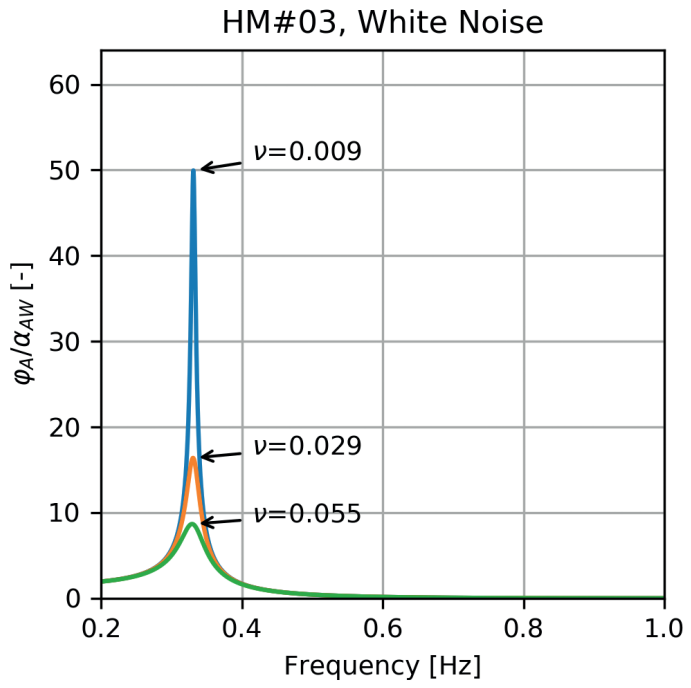

Fig. 10. HM\#03, approximated transfer functions

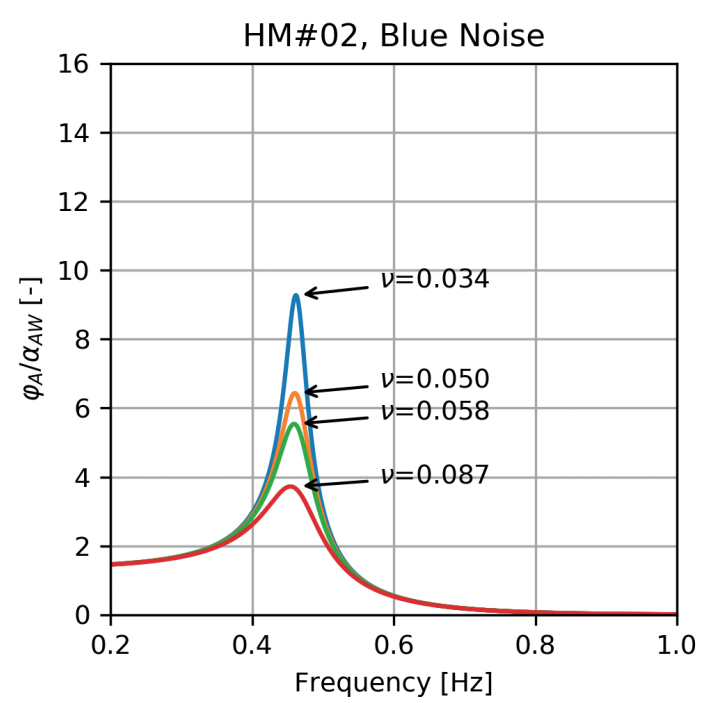

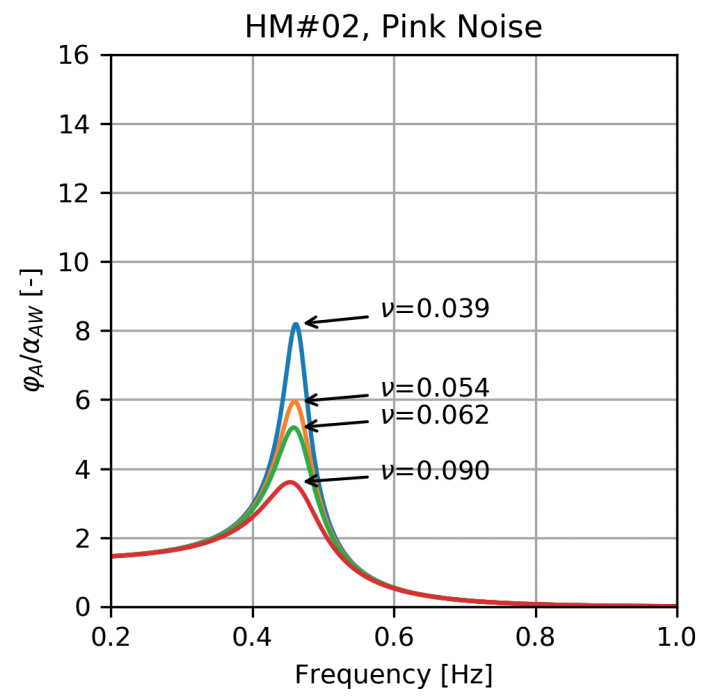

Fig. 9. HM\#02, approximated transfer functions 


\section{UNCERTAINTY ANALYSIS}

Uncertainty analysis (UA) was analysed in two types: Type A and Type B [20]. The RAO curves which were used to final predictions were subjected to UA. The source of errors in Type B analysis is mainly the wave probe error $\varepsilon(\zeta)$ evaluated in probe calibration process and motion tracking system angular precision error $\varepsilon(\varphi)$ provided by manufacturer. The probability distribution of expected value as well as its errors is assumed here as rectangular (uniform) thus uncertainty of measured signal is given by formula:

$$
\begin{aligned}
u\left(\zeta_{A W}\right) & =\frac{\varepsilon(\zeta)}{N \sqrt{3}} \\
u\left(\varphi_{A}\right) & =\frac{\varepsilon(\varphi)}{N \sqrt{3}}
\end{aligned}
$$

The value $N$ in formulas (18) and (19) is the number of harmonics in considered amplitude spectrum.

The dimensionless RAO function $Y \varphi$ might be calculated by formula (3), and is established by indirect measurements. The combined uncertainty is calculated then by partial derivatives of formula (3) as follows:

$$
u_{B}\left(Y_{\varphi}\right)=\sqrt{\left(\frac{\delta Y_{\varphi}}{\delta \zeta_{A W}}\right)^{2} u^{2}\left(\zeta_{A W}\right)+\left(\frac{\delta Y_{\varphi}}{\delta \varphi_{A}}\right)^{2} u^{2}\left(\varphi_{A}\right)}
$$

The main source of errors in Type A uncertainty here is the deviation from approximated and measured RAO characteristics, thus the Type A uncertainty $u_{A}\left(Y_{\varphi}\right)$ is equal to root mean square error of approximation given by equation (16).

The total uncertainty is then calculated as root of sum squared uncertainties of Type A and B:

$$
u\left(Y_{\varphi}\right)=\sqrt{u_{A}^{2}\left(Y_{\varphi}\right)+u_{B}^{2}\left(Y_{\varphi}\right)}
$$

The percentage of total uncertainty in maximum RAO value $Y_{\varphi}\left(f_{R E S}\right)$ at resonant frequency $f_{R E S}$ is calculated from formula:

$$
\frac{u\left(Y_{\varphi}\right)}{Y_{\varphi}\left(f_{R E S}\right)} \cdot 100 \%
$$

and it is presented in Fig. 11 to Fig. 13 as a function of wave frequency

Finally the uncertainty of predicted RMS values of roll motions, from approximated RAO of noise measurements, are calculated as combined uncertainty from formula:

$$
u\left(\varphi_{R M S}\right)=\frac{\delta \varphi_{R M S}}{\delta Y_{\varphi}} \Delta Y_{\varphi}
$$

where root mean square function of roll motions is calculated from combined formulas (6), (7) and (8) as follows:

$$
\varphi_{R M S}=\sqrt{\int S_{\zeta}(\omega) \cdot Y_{\varphi}^{2}(\omega) d \omega}
$$

and the total uncertainty of RAO function is found from:

$$
\Delta Y_{\varphi}=\int u\left(Y_{\varphi}\right) d \omega
$$

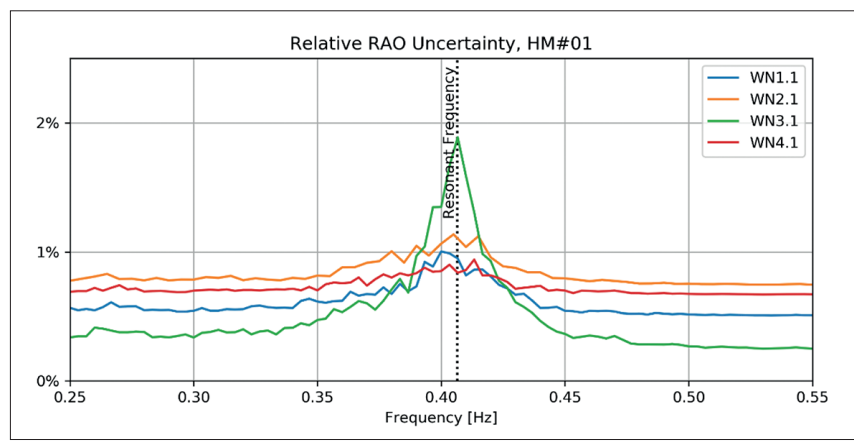

Fig. 11 Relative RAO uncertainty HM\#01

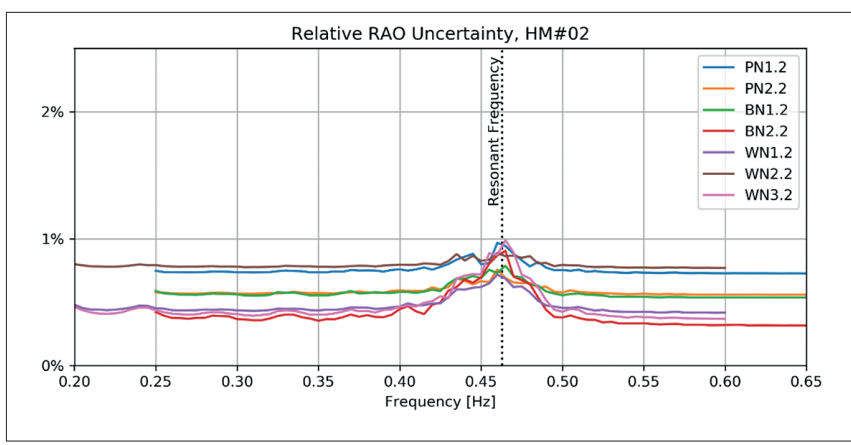

Fig. 12 Relative RAO uncertainty HM\#02

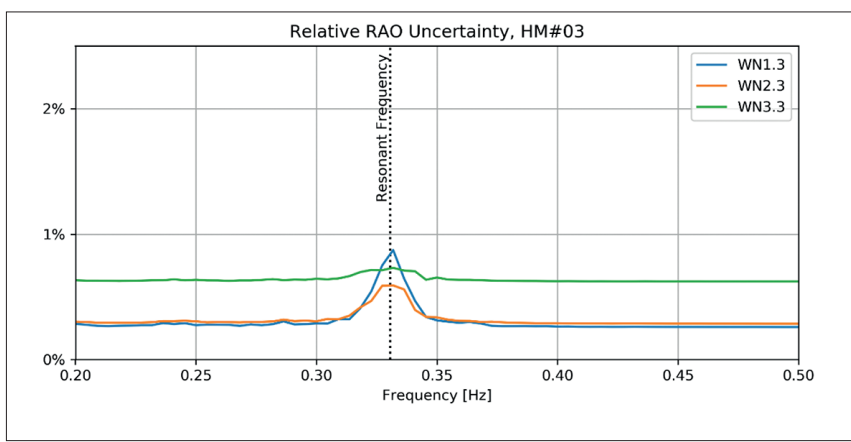

Fig. 13 Relative RAO uncertainty HM\#03

Uncertainty of roll RMS from direct measurements in irregular waves is equal to:

$$
u\left(\varphi_{R M S}\right)=\frac{\varepsilon(\varphi)}{\sqrt{3}}
$$

\section{RESULTS OF ANALYSES}

Equation (13) with modified Froude-Krylov coefficients fits very well to the RAOs evaluated from noise wave experiments. The values of the damping coefficients lie on a straight line in all considered configurations of the tests (Fig. 7). Table 3 presents the results of predictions from direct measurements in the modelled sea waves compared to the predictions calculated from the RAOs. The predicted and measured RMS values were then plotted against each other (Fig. 14). The straight red line depicts the ideal correlation between prediction and measurements, while the grey lines represent $\pm 5 \%$ margin of the actual values. 
Tab. 3. Comparison of roll motion RMS values (measurements in irregular waves and noise RAO-based predictions)

\begin{tabular}{|c|c|c|c|c|c|c|}
\hline & Noise & $u\left(\varphi_{R M S}\right)$ & Irregular & $u\left(\varphi_{R M S}\right)$ & Regular & Description \\
\hline $\mathrm{I} 1.1$ & 2.42 & 0.04 & 2.23 & 0.06 & 1.67 & \multirow[t]{3}{*}{ HM\#01 } \\
\hline I 2.1 & 3.63 & 0.09 & 3.36 & 0.06 & 3.57 & \\
\hline I3.1 & 4.15 & 0.13 & 4.13 & 0.06 & 4.75 & \\
\hline I1.2 & 0.95 & 0.05 & 1.01 & 0.06 & $\mathrm{~N} / \mathrm{A}$ & \multirow[t]{4}{*}{ HM\#02.BN } \\
\hline $\mathrm{I} 2.2$ & 5.21 & 0.10 & 5.01 & 0.06 & $\mathrm{~N} / \mathrm{A}$ & \\
\hline $\mathrm{I} 3.2$ & 7.46 & 0.13 & 7.14 & 0.06 & N/A & \\
\hline $\mathrm{I} 4,2$ & 8.62 & 0.24 & 8.75 & 0.06 & N/A & \\
\hline I1.2 & 0.92 & 0.07 & 1.01 & 0.06 & N/A & \multirow[t]{4}{*}{ HM\#02.PN } \\
\hline $\mathrm{I} 2.2$ & 4.99 & 0.14 & 5.01 & 0.06 & N/A & \\
\hline $\mathrm{I} 3.2$ & 7.15 & 0.18 & 7.14 & 0.06 & N/A & \\
\hline $\mathrm{I} 4,2$ & 8.47 & 0.32 & 8.75 & 0.06 & $\mathrm{~N} / \mathrm{A}$ & \\
\hline I1.2 & 0.90 & 0.04 & 1.01 & 0.06 & N/A & \multirow[t]{4}{*}{$\mathrm{HM} \# 02 . \mathrm{WN}$} \\
\hline $\mathrm{I} 2.2$ & 5.04 & 0.08 & 5.01 & 0.06 & N/A & \\
\hline $\mathrm{I} 3.2$ & 7.34 & 0.11 & 7.14 & 0.06 & N/A & \\
\hline $\mathrm{I} 4,2$ & 8.92 & 0.19 & 8.75 & 0.06 & $\mathrm{~N} / \mathrm{A}$ & \\
\hline I1. 3 & 0.41 & 0.05 & 0.34 & 0.06 & N/A & \multirow[t]{3}{*}{ HM\#03 } \\
\hline I 2.3 & 4.77 & 0.15 & 4.54 & 0.06 & N/A & \\
\hline I 3.3 & 6.51 & 0.32 & 7.25 & 0.06 & N/A & \\
\hline
\end{tabular}

The predicted and measured values were analysed by means of Pearson's correlation factor $R_{f_{o}}$ and the root mean square error (RMSE) given by [21]:

$$
\begin{gathered}
R_{f o}=\frac{1}{N} \sum_{i}^{N} y_{f i} y_{o i} \\
R M S E_{f o}=\sqrt{\frac{1}{N} \sum_{i}^{N}\left(Y_{f i}-Y_{f o}\right)^{2}}
\end{gathered}
$$

where

$$
R_{f o}=\frac{Y_{f i}-\mu_{f}}{\sigma_{f}} y_{f i}, y_{o i}=\frac{Y_{o i}-\mu_{o}}{\sigma_{o}}
$$

The $R_{f o}$ correlation coefficient quantifies the statistically linear correlation between observations (measurements) $Y$ and predictions $Y_{f}$. The squared value of $R_{f o}$ varies within between 0 and 1 .

\section{CONCLUSIONS}

The method presented in this study may be used as an alternative experimental approach to evaluate RAOs. The experiments were carried out in irregular waves with wide bandwidth spectra of colour noise character. The approach might be considered as similar to that proposed by (Bielicki, Bednarek and Kraskowski [22]) where the noise measurements were applied to find predicted roll motions in considered sea states. The approach presented in [22] approximates RAO functions to noise measurements and Froude-Krylov moment in Eq. (13) is calculated basing on different formulae with

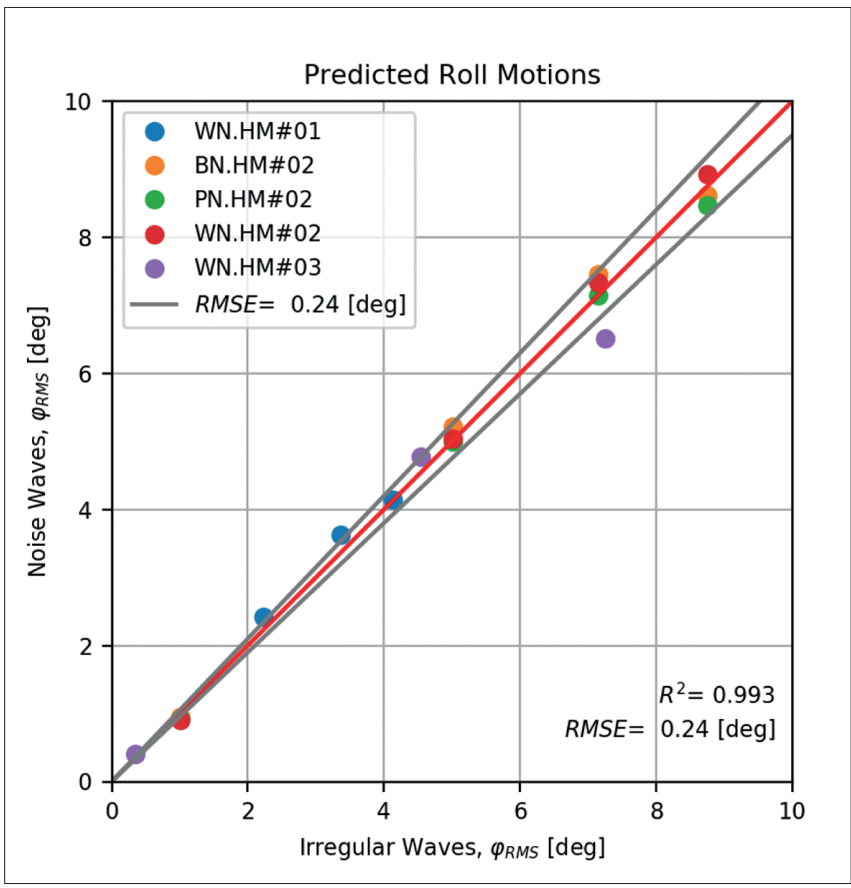

Fig. 14. Correlation plot of measurements against prediction

correction depending on the level of noise input signal. The damping factor is obtained there from roll decay tests and adjusted to considered sea state by iteration. The method presented here allows to apply modified Froude-Krylov moment from Eq. (14), which arises from measurements. 
Besides the damping coefficient is found from the least square approximation of Eq. (13) directly - it exclude the necessity of roll decay tests. Finally the main outcome of the method presented here is that the damping coefficient varies linearly with the RMS values of noise generated waves. The last feature allows to predict roll motions in variety of sea states basing on limited measurements in noise waves. Thus the predicted roll motions in multiple sea state conditions fit reasonably well with measurements in selected irregular waves (sea conditions), as confirmed by a squared Pearson's correlation above 0.99 and a RMSE below 0.25 [deg]. The noise wave-based measurement may be extended for other motions, like heave and pitch.

\section{ACKNOWLEDGEMENTS}

This research was financed by the Ministry of Science and Higher Education of the Republic of Poland and by the Maritime Advanced Research Centre CTO S.A.

\section{REFERENCES}

1. M. Reichel, "Longitudinal motion due to action of tunnel thrusters," Polish Maritime Research, vol. 25, no. Sepcial Issue, pp. 74-79, 2018.

2. H. Olszewski and H. Ghaemi, "New concept of numerical ship motion modelling for total ship operability analysis by integrating ship and environment under one overall system," Polish Maritime Research Special Issue, no. DOI: 10.2478/ pomr-2018-0020, pp. 36-41, 2018.

3. S. Mousaviraad, P. Carrica, J. Huang and F. Stern, "CFD Prediction of Ship Response to Severe Ocean Waves and Wind," in 27th Symposium on Naval Hydrodynamics, Seoul, Korea, 2008.

4. C. D. Simonsen, J. F. Otzen, S. Joncquez and F. Stern, "EFD and CFD for KCS heaving and pitching in regular head waves," Journal of Marine Science and Technology (Japan), vol. 18, no. DOI: 10.1007/s00773-013-0219-0, pp. 435-459, 2013.

5. B. J. Guo, S. Steen and G. B. Deng, "Seakeeping prediction of KVLCC2 in head waves with RANS," Applied Ocean Research, vol. 35, no. DOI: 10.1016/j.apor.2011.12.003, pp. 56-67, 2012.

6. K. Niklas and H. Pruszko, "Full scale CFD seakeeping simulations for case study ship redesigned from V-shaped bulbous bow to X-bow hull form," Applied Ocean Research, vol. 89, no. DOI: 10.1016/j.apor.2019.05.011, pp. 188-201, 2019.

7. J. Jia, Z. Chen, C. Chen i H. Ren, „Time-domain hydroelastic analysis of nonlinear motions and loads on a large bow flare ship in high irregular seas.," Journal of Marine Science and Technology (Japan), tom 25(2), pp. 426-454, 2020.

8. J. Jiao, S. Sun, J. Lee, C. Adenya, H. Ren, C. Chen and D. Wang, "A comprehensive study on the seakeeping performance of high speed hybrid ships by $2.5 \mathrm{D}$ theoretical calculation and different scaled model experiments," Ocean Engineering, vol. 160, pp. 197-223, 2018.

9. J. Jiao, C. Chen i H. Ren, „A comprehensive study on ship motion and load responses in short-crested irregular waves," International Journal of Naval Architecture and Ocean Engineering, tom 11, nr DOI: 10.1016/j.ijnaoe.2018.07.003, pp. 364-369, 2019.

10. X. Wu, L. Tao i Y. Li, „Nonlinear roll damping of ship motions in waves," Journal of Offshore Mechanics and Arctic Engineering, tom 127, nr DOI: 10.1115/1.1951780, pp. 205211, 2005.

11. M. St. Denis and W. Pierson, "On the motion of ships in confused seas," Soc. Nav. Archit. Mar. Eng., vol. Trans. 61, pp. 280-354, 1953.

12. J. Journee and W. Massie, Introduction in Offshore Hydromechanics, Delft: Delft University of Technology, 2001.

13. O. Rice, "Mathematical Analyses of Random Noise," Bell System Technical Journal, Vols. Vols. 23, 24, 1945.

14. J. Dudziak, Teoria Okrętu, Gdańsk: Fundacja Promocji Przemysłu Okrętowego i Gospodarki Morskiej, 2008.

15. S. Chakrabarti, „Physical Model Testing of Floating Offshore Structures," w Dynamic Positioning Conference, Houston, USA, 1998.

16. M. Drzewiecki and W. Sulisz, "Generation and propagation of nonlinear waves in a towing tank," Polish Maritime Research, no. DOI: 10.2478/pomr-2019-0014, pp. 125-133, 2019.

17. ITTC, "Report of the Seakeeping Committee," in Proceedings of 12th International Towing Tank Conference, The Hague, 1978.

18. W. J. Pierson and L. Moskowitz, "A proposed spectral from for fully developed wind seas based on the similarity theory of S.A. Kitaigorodskii," Journal of Geophysical Research, vol. 69, pp. 5181-5203, 1964.

19. K. Hasselmann et al., „Measurement of wind-wave growth and swell decay during the Joint Nort Sea Wave Project (JONSWAP)," Deutschen Hydrographischen Institut, Hamburg, 1973. 
20. "Evaluation of measurement data - Guide to the expression of uncertainty in measurement," in JCGM 100:2008, 2008.

21. A. Barnston, "Correspondence Among the Correlation, RMSE and Heidke Forecast Verification Measures," American Meteorological Society, Climate Analysis Center, NMC/NWS/NOAA, Washingto D.C., 1992.

22. S. Bielicki, A. Bednarek and M. Kraskowski, "Evaluation of Response Amplitude Operator of Ship Roll Motions," in Proceedings of the ASME 2017 36th International Conference on Ocean, Offshore and Arctic Engineering, Trondheim, 2017.

\section{CONTACT WITH THE AUTHOR}

Sebastian Bielicki

e-mail: sebastian.bielicki@cto.gda.pl

Centrum Techniki Okrętowej S.A. Szczecińska 65, 80-392 Gdańsk

POLAND 